OPEN ACCESS

Edited by: Artur Mayerhofer, Ludwig Maximilian University of Munich, Germany

Reviewed by:

Klaus Steger,

Justus-Liebig University, Germany

Hernan E. Lara,

University of Chile, Chile

${ }^{*}$ Correspondence:

Betina González

bgonzalez@ffyb.uba.ar

Specialty section: This article was submitted to

Reproduction,

a section of the journal

Frontiers in Endocrinology

Received: 18 November 2020 Accepted: 30 December 2020

Published: 19 February 2021

Citation:

González CR and González B (2021) Exploring the Stress Impact in the

Paternal Germ Cells Epigenome:

Can Catecholamines Induce

Epigenetic Reprogramming?

Front. Endocrinol. 11:630948.

doi: 10.3389/fendo.2020.630948

\section{Exploring the Stress Impact in the Paternal Germ Cells Epigenome: Can Catecholamines Induce Epigenetic Reprogramming?}

\author{
Candela R. González ${ }^{1}$ and Betina González ${ }^{2 *}$ \\ ${ }^{1}$ Centro de Estudios Biomédicos Básicos, Aplicados y Desarrollo (CEBBAD), Universidad Maimónides, Buenos Aires, \\ Argentina, ${ }^{2}$ Instituto de Investigaciones Farmacológicas (Universidad de Buenos Aires-Consejo Nacional de Investigaciones \\ Científicas y Técnicas), Ciudad Autónoma de Buenos Aires, Buenos Aires, Argentina
}

Spermatogenesis is characterized by unique epigenetic programs that enable chromatin remodeling and transcriptional regulation for proper meiotic divisions and germ cells maturation. Paternal lifestyle stressors such as diet, drug abuse, or psychological trauma can directly impact the germ cell epigenome and transmit phenotypes to the next generation, pointing to the importance of epigenetic regulation during spermatogenesis. It is established that environmental perturbations can affect the development and behavior of the offspring through epigenetic inheritance, including changes in small non-coding RNAs, DNA methylation, and histones post-translational modifications. But how male germ cells react to lifestyle stressors and encode them in the paternal epigenome is still a research gap. Most lifestyle stressors activate catecholamine circuits leading to both acute and long-term changes in neural functions, and epigenetic mechanisms show strong links to both long-term and rapid, dynamic gene expression regulation during stress. Importantly, the testis shares a molecular and transcriptional signature with the brain tissue, including a rich expression of catecholaminergic elements in germ cells that seem to respond to stressors with similar epigenetic and transcriptional profiles. In this minireview, we put on stage the action of catecholamines as possible mediators between paternal stress responses and epigenetic marks alterations during spermatogenesis. Understanding the epigenetic regulation in spermatogenesis will contribute to unravel the coding mechanisms in the transmission of the biological impacts of stress between generations.

Keywords: male germ cells, epigenetics, catecholamines, dopamine receptor, adrenergic receptor

\section{INTRODUCTION}

Stress is a phenomenon fundamental to survival, in which complex and timely physiological and behavioral responses, allow the individual to adapt to the dynamic challenges of the environment and restore body homeostasis (1). The stress response is activated by the sympathoneural and sympathoadrenomedullary systems that secrete catecholamines, which in turn activates the 
hypothalamus-pituitary-adrenal (HPA) axis to secrete glucocorticoids. The interplay between these circuits systemically promotes metabolic and behavioral changes that are transient and adaptive; however, the prolonged sympathetic stimulation and increased glucocorticoid levels during chronic stress has been associated with long-lasting maladaptive responses (2). In the last years, the discovery of epigenetic mechanisms that could alter the sperm information and transmit stress-related phenotypes to the offspring was a huge breakthrough for the male reproduction field (3). It is now clear that pathophysiological effects of stress are not confined to the individual, but stress can affect the first generation offspring and even extend across multiple generations through the epigenetic reprogramming of male germ cells (4-6).

Epigenetic information in male germ cells involves changes in small non-coding RNAs, paternal DNA methylation and histones post-translational modifications (PTMs) patterns that modulate gene expression in response to basal transcriptional programs and environmental stressors (7). Spermatogenesis is characterized by a unique epigenetic program that enables chromatin remodeling to protect paternal DNA, and a fine transcriptional regulation required for proper meiotic divisions and sperm maturation (Figure 1A). Within male germ cells, changes in epigenetic states are critical for the silencing of transposable elements, paternal genes imprinting, several aspects of meiosis, post-meiotic gene silencing and DNA compaction (9). Once meiosis is completed, the hyperacetylation of histones H3/ H4 initiates the essential histone-to-protamine replacement that enables chromatin remodeling and compaction during spermiogenesis (10-13). It was recently found that protamines also carry several PTMs (14), suggesting the existence of a "protamine code" that could be involved in the epigenetic mechanisms that control the incorporation of maternal histones to paternal DNA after fertilization (15). Interestingly, a small percentage of histones, $10-15 \%$ in humans and $1-8 \%$ in mice, are retained in sperm chromatin (16-18) being their location associated with promoters of functional genes during spermatogenesis and at early embryonic development (7, 10, 11, 19). Active transcription in male germ cells takes place in the stages of spermatogonia, spermatocytes, and round spermatids, where epigenetic patterns are established $(3,7)$. Therefore, these spermatogenic stages are considered windows of vulnerability where the paternal epigenome could be reprogrammed by environmental stressors (20).

The catecholamine and glucocorticoid systems elicit dynamic molecular adaptations of the central nervous system (CNS) during stress, contributing to long-term consequences on physiological and behavioral traits that can be transmitted to the offspring (2123). So far, a clear link has been demonstrated between glucocorticoid receptor (GR) activation by corticosterone

\footnotetext{
Abbreviations: H, histone; PTMs, post-translational modifications; DA, dopamine; NE, nor-epinephine; TH, tyrosine hydroxylase; AADC or DDC, aromatic-L-aminoacid-decarboxylase; $\mathrm{DBH}$, dopamine-beta-hydroxylase; PNMT, phenylethanolamine-N-methyltransferase (PNMT); DRD, DA receptor; $\mathrm{ADR}$, adrenergic receptor; COMT, catabolic catechol-O-methyltransferase; MAO, monoamine oxidase; HPA, hypothalamic-pituitary-adrenal; CNS, central nervous system; BDNF, brain-derived neurotrophic factor.
}

administration and increased levels of microRNAs and DNA methylation in sperm $(24,25)$. However, the catecholamines specific impact on the paternal epigenome is still a research gap. Here, the question arises: can germ cells react to catecholamines signaling and encode it in different epigenetic marks in the paternal genome? To tackle this question, we discuss how the testis shares a molecular and transcriptional signature with the brain tissue, including a rich expression of catecholaminergic elements in germ cells that seem to respond to stressors with similar epigenetic and transcriptional profiles. In this minireview, we put on stage the action of catecholamines as potential regulators of the stress epigenetic memory encoding in germ cells.

\section{Epigenetic Mechanisms Related to Catecholamines Signaling}

Most lifestyle stressors activate catecholamine circuits leading to both acute and long-term changes in neural functions, and epigenetic mechanisms are strongly suspected in both longterm and rapid, dynamic gene expression regulation during stress (26). Environmental stressors rapidly activate the sympathetic system and induce changes in the production and secretion of neurotransmitters and stress hormones including the catecholamines dopamine (DA) and nor-epinephrine (NE)/ epinephrine (E), which orchestrate central and peripheral downstream effects that enable the behavioral and systemic response to stress. Dopaminergic tissues express the rate-limiting tyrosine hydroxylase $(\mathrm{TH})$ and the aromaticL-aminoacid-decarboxylase (AADC or DDC), that convert L-tyrosine to DA. Adrenergic tissues also express dopaminebeta-hydroxylase $(\mathrm{DBH})$ that further converts $\mathrm{DA}$ to $\mathrm{NE}$, and the phenylethanolamine-N-methyltransferase (PNMT) converts $\mathrm{NE}$ to $\mathrm{E}$ in the adrenal medulla $(27,28)$. The stress response rapidly release catecholamines that activate the HPA axis, which in turn induces both neuronal and non-neuronal expression of $\mathrm{TH}$, DDC and DBH, increasing central and peripheral catecholamine production $(27,28)$. Catecholamines bind to $G$ protein-coupled receptors (GPCRs) that signal though cAMP and $\mathrm{Ca}^{2+}$ second messengers. DA effects are mediated by two types of DA receptors (DRDs): D1-like (D1, D5), that are coupled to $\mathrm{G \alpha}_{\mathrm{s}} / \mathrm{G \alpha}_{\mathrm{olf}}$ and rise cAMP levels, and D2-like (D2, D3, D4) DRDs, that are coupled to $\mathrm{G \alpha}_{\mathrm{i}}$ and blunt cAMP levels (29). NE/E effects are mediated by activation of three types and nine subtypes of adrenergic receptors (ADRs): alpha1- $(\alpha 1 \mathrm{a} / \mathrm{c}, \alpha 1 \mathrm{~b}, \alpha 1 \mathrm{~d})$, coupled to $\mathrm{G \alpha}_{\mathrm{q}}$ to increase cytoplasmic $\mathrm{Ca}^{2+}$ levels, alpha2- $(\alpha 2 \mathrm{a}, \alpha 2 \mathrm{~b}, \alpha 2 \mathrm{c})$, coupled to $\mathrm{G}_{\mathrm{i}}$, and beta- $(\beta 1, \beta 2, \beta 3)$ ADRs, coupled to $G \alpha_{s}(30)$. Upon production and release, catecholamines are rapidly deactivated by the catabolic catechol-O-methyltransferase (COMT) and monoamine oxidase (MAO) enzymes $(27,28)$.

The regulation of DA and NE synthesis, release and signaling is extremely sensitive to environmental perturbations, affecting gene expression through epigenetic mechanisms in the brain (31-33). Catecholamine receptors downstream effects are related to the modulation of cAMP and $\mathrm{Ca}^{2+}$ levels, that control signaling effectors like protein kinases PKA and PKC, and calmodulin kinases such as CaMKII $(29,34,35)$. Stressinduced overstimulation of $\mathrm{G \alpha}_{\mathrm{s}}$-coupled D1-DRDs and $\beta$ ADRs was linked to increased oxidative stress and PKA 
A

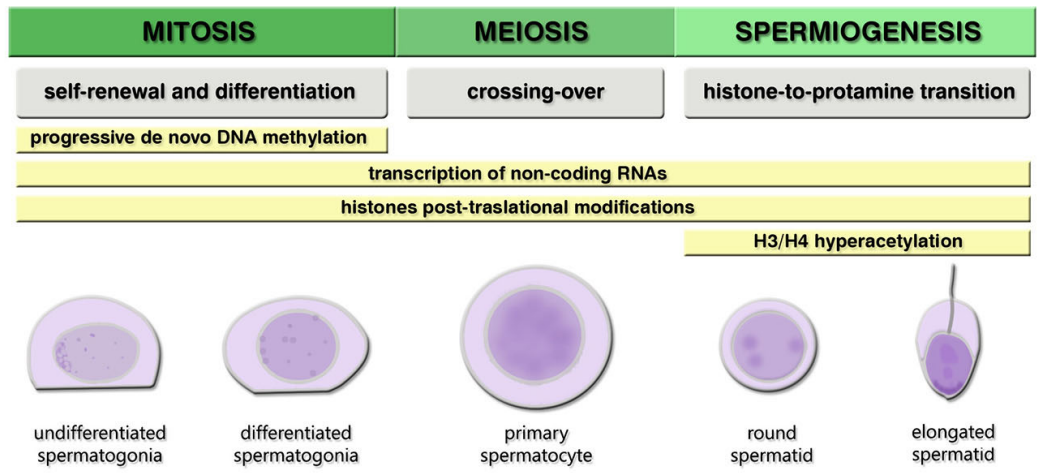

B

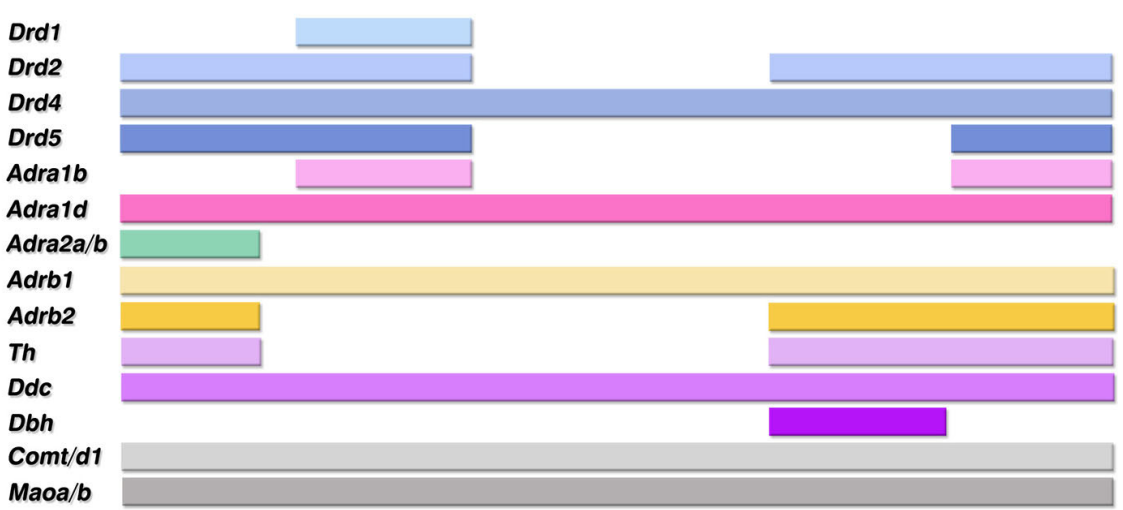

C

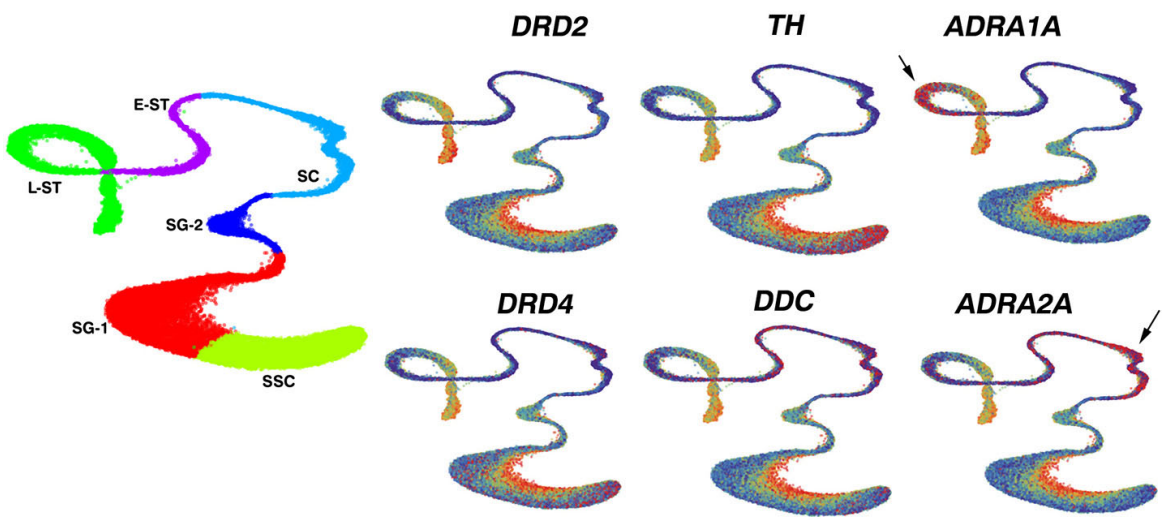

FIGURE 1 | Epigenetic programming during spermatogenesis and expression of the catecholaminergic system components in different germ cell stages of the mouse and human spermatogenesis. (A) Curated stages of spermatogenesis available at the Gene Expression Omnibus (GEO) database. Yellow bars show the epigenetic mechanisms that contribute to key functional events (gray) characteristic of each cell stage during mitosis, meiosis and spermiogenesis, where environmental stressors are most able to reprogram epigenetic marks. (B) Gene expression profile in mouse spermatogenic cells, obtained from cell-stage specific RNA-seq and single-cell RNA-seq datasets GEO database. The colored bars depict at which cell stage all datasets reported positive transcript detection for the catecholamine receptors and enzymes genes [mean RNA-seq RPKM/FPKM > 0.05 and single-cell RNA-seq log(sum normalized expression in the cluster + 1) > 1.2] The picture shows: dopamine receptors from the D1 family Drd1, Drd5, and D2 family Drd2, Drd4; adrenergic receptors from the $\alpha 1$-subtype Adra1b, Adra1d, $\alpha 2$ subtype Adra2a, Adra2b, and $\beta$-subtype Adrb1, Adrb2; dopamine synthesizing enzymes tyrosine hydroxylase (Th) and aromatic-L-aminoacid-decarboxylase (Ddc); nor-epinephrine converting enzyme dopamine-beta-hydroxylase (Dbh); catecholamine eliminating enzymes catechol-O-methyl-transferase Comt, Comtd1, and monoamine oxydase Maoa, Maob. Genes within the same family that showed coincident expression pattern are depicted together. We found no consistent expression of Drd3, Adra1a, Adra2c, and Adrb3 between datasets for any cell stage. (C) Gene expression visualization for selected genes in the Human Testis integrated dataset, available at the UCSC cell browser (https://testis.cells.ucsc.edu/), that combines the currently available human testis single-cell RNA-seq datasets (8). We selected Uniform Manifold Approximation and Projection (UMAP) for dimension reduction to plot the quantitative gene expression pattern in increasing blueto-red gradient color code. Left plot shows the cells clusters distribution: SSC, spermatogonial stem cells; SG-1, spermatogonia cluster 1, SG-2, spermatogonia cluster 2 committed to meiosis; SC, spermatocytes; E-ST, early spermatids; L-ST, late spermatids. Arrows indicate specific high red detection for ADRA1A in late spermatids, and ADRA2A in spermatocytes, in the Human Testis integrated dataset that was not detected in the mouse datasets. 
recruitment of mitogen-activated protein kinases (MAPKs) (3638), which translocate into the nucleus to phosphorylate and activate several transcription factors including the cAMP response element-binding protein $(\mathrm{CREB})$, activator protein 1 (AP-1), transcription activator Elk-1, nuclear factor $\kappa \mathrm{B}(\mathrm{NF} \kappa \mathrm{B})$ and $\mathrm{H} 3$ histones, to control target gene expression $(34,36,37)$. So far, the best characterized stress-induced epigenetic effects involve increased $\mathrm{H} 3$ phosphoacetylation $(26,33)$ and changes in DNA and $\mathrm{H} 3 \mathrm{~K} 9 / \mathrm{K} 27$ methylation patterns in target genes, affecting components of the stress system like corticotropin releasing hormone $(\mathrm{CRH}), \mathrm{GR}$ and $\mathrm{MAO}-\mathrm{A}$, trophic factors like brain-derived neurotrophic factors (BDNF), as well as inflammation-, oxidative-, mitochondrial-, and endoplasmic reticulum stress-related genes $(26,36,37,39)$. Importantly, many stress-induced epigenetic effects depend on GR activation, a nuclear receptor that elicits both genomic and non-genomic changes in gene expression by direct binding to DNA, and by forming complexes with MAPKs (40, 41), and epigenetic effectors like chromatin modifying enzymes and microRNAs (42). Moreover, GR binds to TH, DBH, and PNMT promoters to increase gene expression and catecholamine production (27), and it was also show to control catecholamines receptors expression such as $\alpha 1$ - and $\beta$-ADRs $(43,44)$. But if these stress mechanisms can also impact the testis and establish an epigenetic memory in germ cells has not been fully elucidated.

\section{Daddy Has Two Brains}

The testis shares a close transcriptional and proteomic signature with the brain, as it was shown in tissue microarray and proteomic studies in human and mice (45-47). It is clear that the interstitial compartment behaves as a diffuse neuroendocrine (paraneuron) system, where most cell types share properties with neurons, including production of amine and peptide hormones/ transmitters, and specific markers of neural determination (48, 49). Pioneer studies in the human and primate testis showed that the interstitial compartment, together with an extrinsic sympathetic innervation provided by the spermatic nerves $(50,51)$, has an intrinsic catecholaminergic input provided by neuron-like APUD (amine precursor uptake and decarboxylation) cells, that cooperate with the autonomous brain system to regulate tissue homeostasis (52-54).

The close relationship between brain and reproductive tissues can be traced even to the mature sperm. Recent work by Ramírez-Reveco et al. (55), postulated the original and controversial idea that sperm acrosome reaction includes several steps that recall the process of presynaptic secretion. The authors also proposed that the common embryonic origin between the testis and nervous system could explain the presence of "neural elements" in the sperm, including DA and NE transporters and receptors (56-58). Interestingly, recent evidences showed that the sex determining region on the $\mathrm{Y}$ chromosome (SRY) transcription factor, responsible for the differentiation of the bipotent gonadal ridge into the testis, behaves as a catecholaminergic program inductor that controls voluntary movement in adult brain dopaminergic areas $(59,60)$. SRY was found to potentiate DA synthesis and metabolism by binding to $\mathrm{TH}$ enhancer, and to increase $\mathrm{DDC}$, DRD2, and
MAO-A levels in dopaminergic neurons (59). Moreover, testosterone through androgen receptor activation was found to participate in the regulation of cortical DA neurotransmission, modulating TH levels, DA metabolism, and cognition in male rodents (61).

So far, the best characterized actions of catecholamines in the testis are related to their targets in the interstitial compartment and the control of steroidogenesis $(52,53,62)$, whereas their possible direct effects in the seminiferous tubule have been sidelined. Despite research on specific catecholamine actions during spermatogenesis was neglected, there are welldocumented examples of sympathomimetic drugs, e.g., cocaine, that affect the male germ cell epigenome (63-66). In the last years, evidence has emerged pointing to modifications in sperm DNA methylome in paternal stress models involving cocaine intake $(64,65)$. We and others have reported the effects of cocaine on specific $\mathrm{H} 3 / \mathrm{H} 4$ PTMs related to altered epigenetic marking of BDNF in sperm (63), and to the silencing of gene transcription and the histone-to-protamine replacement through a DRD1-dependent mechanism in maturing sperm cells (66). Moreover, we showed for the first time that cocaine increases the testicular expression of $\mathrm{TH}$ (67) and induces a down-regulation of DRDs in mouse germ cells (66), similarly to the cocaine mechanism described in the brain. Interestingly, we found similar changes on germ cells H3/H4 PTMs after either DRD1inhibitor or cocaine treatment, an effect known in the brain as the "inverted U-shaped DA response," where stimulation above and below the optimal level will equally decrease function and have similar detrimental effects (68). To our knowledge, this was the first report that proposed a catecholaminergic pathway as a mechanism of epigenetic marks encoding in male germ cells. Despite all these data, it has not been investigated the cellular stage at which male germ cells may acquire catecholaminergic components and their potential role in paternal epigenome reprogramming.

\section{An Open Window for Catecholamine- Induced Epigenetic Reprogramming}

It is actually established that environmental stressors may influence the male germline differently depending on timing (20). Each spermatogenic stage has a characteristic epigenetic landscape that enables the complex transcriptional programs that drive mitosis, meiosis and spermiogenesis, being susceptible to environmental interactions with their active epigenetic machinery (3) (Figure 1A). This provides evidence of the broad timing of plasticity during spermatogenesis. However, there are still research gaps concerning by which mechanisms and when in the germ cell maturation stage epigenetic marks can be programmed.

Research on catecholaminergic components expression during specific stages of spermatogenesis is scarce and sometimes inconclusive. To overcome the gaps in the literature and bring a complete scenario, we conducted a query at the Gene Expression Omnibus Database (GEO) for publicly available high-throughput RNA sequencing (bulk and single-cell RNAseq) datasets in purified male germ cells populations. Table $\mathbf{1}$ shows the details of the curated datasets. We analyzed the normalized expression reported for gene transcripts of interest 
TABLE 1 | Datasets selected from the Gene Expression Omnibus Database (GEO).

\begin{tabular}{|c|c|c|c|c|}
\hline Species & Method & Cell type & Dataset & Reference \\
\hline Mouse & RNA-seq & $\begin{array}{l}\text { Undifferentiated spermatogonia (Thy } 1+\text { ) } \\
\text { Differentiated spermatogonia (Kit+) } \\
\text { Primary spermatocyte } \\
\text { Round spermatid }\end{array}$ & GSE49622 & Hammoud et al. (69) \\
\hline Mouse & RNA-seq & $\begin{array}{l}\text { Primary spermatocyte } \\
\text { Round spermatid }\end{array}$ & GSE43717 & Soumillon et al. (70) \\
\hline Mouse & RNA-seq & Differentiated spermatogonia (cKit+) & GSE89502 & Maezawa et al. (71) \\
\hline Mouse & RNA-seq & Undifferentiated spermatogonia (PLZF+ cKIT-) & GSE107124 & La et al. (72) \\
\hline Mouse & scRNA-seq & $\begin{array}{l}\text { Undifferentiated spermatogonia (Gfra1+) } \\
\text { Primary spermatocyte } \\
\text { Round spermatid } \\
\text { Elongated spermatid }\end{array}$ & GSE112393 & Green et al. (73) \\
\hline Mouse & scRNA-seq & Undifferentiated spermatogonia (ID4-EGFP+) & GSE108974 & Hermann et al. (74) \\
\hline
\end{tabular}

in each study, and selected those genes that showed positive expression for each specific cell stage in all datasets (Figure 1B). We also analyzed the human cell-specific single-cell RNA-seq data in the Human Testis integrated dataset (8), available at UCSC cell browser portal (https://testis.cells.ucsc.edu/), that combines the currently available single-cell RNA-seq human testis datasets (Figure 1C). Overall, we detected expression for catecholaminergic receptors and metabolic enzymes throughout the mouse and human spermatogenesis, which suggest that male germ cells are both a source and a target of catecholamines.

In the adult testis, undifferentiated spermatogonia stem cells (SSCs) must achieve a stable balance between self-renewal and differentiated spermatogonia, which commit to meiosis and give rise to primary spermatocytes. As it is shown in Figure 1B, differentiated spermatogonia are the spermatogenic stages that show most expression of cathecolaminergic receptors mRNAs, including DRDs Drd1/5, Drd2/4, $\alpha 1$-ADRs Adra1b/d, $\alpha 2$-ADRs $A d r a 2 a / b$, and $\beta$-ADRs Adrb1/2. Catecholaminergic receptors mRNAs expression declines at meiotic stages, but once meiosis is complete, round and elongated spermatids seem to reactivate the expression of Drd2/5, Adra1b, and Adrb2 (Figure 1B). In addition, we reported DRD1 expression in spermatogonia (67), whereas others found DRD2 in pre- and post-meiotic germ cells with predominant staining in spermatogonia (57). The $\alpha 1$-ADR immunodetection was observed from spermatogonia to elongated spermatids $(75,76)$, and specific Adralb was reported in early spermatocytes and linked to subfertility (77). The expression data visualization available for the Human Testis dataset (Figure 1C) followed similar profiles to the mouse data, showing DRD2 expression in undifferentiated spermatogonia (SSC and SG-1) and late spermatid stages (L-ST), and scattered high DRD4 expression throughout all spermatogenic stages. Interestingly, the human data also showed specific profiles of $\alpha$-ADRs transcripts, where $\alpha 1$-type ADRA1A and $\alpha 2$-type $A D R A 2 A$ appear highly expressed in late spermatids and spermatocytes, respectively (Figure 1C).

The spermatogonia stages seem to be vulnerable for stressinduced epigenetic reprogramming since they reside outside the blood-testis barrier, being potentially exposed to all sources of catecholamines available in the testis, either plasmatic, or locally produced. The epigenetic status of spermatogonia shifts dramatically to either enter mitosis to self-renew or differentiate to type B and commit to meiosis. Undifferentiated spermatogonia have no expression of the repressive mark H3K9me2 nor the DNA methyltransferases Dnmt3a2/3b, whereas differentiated spermatogonia have increased $\mathrm{H} 3 \mathrm{~K} 9 \mathrm{me} 2$ and upregulated Dnmt3a2/3b (78) which are maintained until round spermatid stage to make new DNA methylation patterns $(7,79)$. In line with this, we found that cocaine treatment altered Dnmt3a/b and Tet 1 , and increased 5-meC levels in mouse germ cells (65). Also, recent studies have shown that both DA via DRD1 and NE via $\beta$-ADRs induce alterations in DNA methylation patterns in the CNS $(33,80)$. Moreover, we have recently reported a U-shaped DRD1-dependent key testicular mechanism mediating cocaine-triggered increase in silent chromatin mark H3K27me3, decrease in active promoter mark $\mathrm{H} 3 \mathrm{~K} 4 \mathrm{me}$, and increase in H4K16ac mark involved in histone to protamine replacement (66). Interestingly, activating H3K4me3 and reppresive $\mathrm{H} 3 \mathrm{~K} 27 \mathrm{me} 3$ are bivalent marks simultaneously present at key promoters of embryonic developmental genes in both the spermatogonia and the retained nucleosomes in the mature sperm, carrying instructions for future embryo development $(16,17,69)$.

The mouse mRNA profile shows that catecholamine inactivating enzymes Comt/d1 and Maoa/b are detected throughout the entire spermatogenic process, suggesting that all germ cell types actively detoxify catecholamines. Also, spermatogonia and spermatids show $T h$ and $D d c$ expression, indicative of dopaminergic identity. Moreover, spermatids seem to reactivate $T h$ together with $D b h$ expression. This synthesizing enzymes profile suggest that male germ cells could be producing $\mathrm{NE}$ in the adluminal compartment, whereas DA could be the main catecholamine synthesized at the basal compartment by the undifferentiated SSCs. Recent groundbreaking work by Lepack et al. (81) showed that DA can associate directly with H3K4me3 to initiate an epigenetic marking of the chromatin called dopaminylation. They also demonstrated that histone dopaminylation in dopaminergic brain areas is involved in gene transcriptional programs that respond to cocaine consumption and craving (81). This work shows that DA synthesis could exert an epigenetic autocrine effect on its own, regardless of receptor activation, which sets a new paradigm from which to consider the possible consequences in germ cells H3K4me3 encoding. 
In summary, we have put the spotlight on catecholamines as possible mediators between the stress response and epigenetic marks alterations during spermatogenesis. The expression of catecholaminergic components during germ cell maturation may point to these stress hormones as novel epigenetic regulators during spermatogonial and spermiogenic phases. Also, the expression of catecholaminergic components during spermiogenesis, when massive epigenetic events drive chromatin remodeling and nuclear compaction to produce mature spermatozoa, points to post-meiotic germ cells as a vulnerable window for stress-induced epigenetic reprogramming that

\section{REFERENCES}

1. Godoy LD, Rossignoli MT, Delfino-Pereira P, Garcia-Cairasco N, de Lima Umeoka EH. A Comprehensive Overview on Stress Neurobiology: Basic Concepts and Clinical Implications. Front Behav Neurosci (2018) 12:127. doi: 10.3389/fnbeh.2018.00127

2. Radley J, Morilak D, Viau V, Campeau S. Chronic stress and brain plasticity: Mechanisms underlying adaptive and maladaptive changes and implications for stress-related CNS disorders. Neurosci Biobehav Rev (2015) 58:79-91. doi: 10.1016/j.neubiorev.2015.06.018

3. Bale TL. Lifetime stress experience: transgenerational epigenetics and germ cell programming. Dialogues Clin Neurosci (2014) 16(3):297-305. doi: 10.31887/DCNS.2014.16.3/tbale

4. Rodgers AB, Bale TL. Germ Cell Origins of Posttraumatic Stress Disorder Risk: The Transgenerational Impact of Parental Stress Experience. Biol Psychiatry (2015) 78(5):307-14. doi: 10.1016/j.biopsych.2015.03.018

5. Hanson MA, Skinner MK. Developmental origins of epigenetic transgenerational inheritance. Environ Epigenet (2016) 2(1):dvw002. doi: 10.1093/eep/dvw002

6. van Steenwyk G, Roszkowski M, Manuella F, Franklin TB, Mansuy IM. Transgenerational inheritance of behavioral and metabolic effects of paternal exposure to traumatic stress in early postnatal life: evidence in the 4th generation. Environ Epigenet (2018) 4(2):dvy023. doi: 10.1093/eep/ dvy023

7. Rajender S, Avery K, Agarwal A. Epigenetics, spermatogenesis and male infertility. Mutat Res (2011) 727(3):62-71. doi: 10.1016/j.mrrev.2011. 04.002

8. Soraggi S, Riera M, Rajpert-De Meyts E, Schierup MH, Almstrup K. Evaluating genetic causes of azoospermia: What can we learn from a complex cellular structure and single-cell transcriptomics of the human testis? Hum Genet (2020). doi: 10.1007/s00439-020-02116-8

9. Zamudio NM, Chong S, O’Bryan MK. Epigenetic regulation in male germ cells. Reprod (Cambridge England) (2008) 136(2):131-46. doi: 10.1530/REP07-0576

10. Hazzouri M, Pivot-Pajot C, Faure AK, Usson Y, Pelletier R, Sèle B, et al. Regulated hyperacetylation of core histones during mouse spermatogenesis: involvement of histone deacetylases. Eur J Cell Biol (2000) 79(12):950-60. doi: 10.1078/0171-9335-00123

11. Steilmann C, Paradowska A, Bartkuhn M, Vieweg M, Schuppe HC, Bergmann $\mathrm{M}$, et al. Presence of histone $\mathrm{H} 3$ acetylated at lysine 9 in male germ cells and its distribution pattern in the genome of human spermatozoa. Reproduction Fertil Dev (2011) 23(8):997-1011. doi: 10.1071/RD10197

12. Shirakata Y, Hiradate $Y$, Inoue H, Sato E, Tanemura K. Histone h4 modification during mouse spermatogenesis. J Reprod Dev (2014) 60 (5):383-7. doi: 10.1262/jrd.2014-018

13. Bao J, Bedford MT. Epigenetic regulation of the histone-to-protamine transition during spermiogenesis. Reproduction (2016) 151(5):R55-70. doi: 10.1530/REP-15-0562

14. Brunner AM, Nanni P, Mansuy IM. Epigenetic marking of sperm by posttranslational modification of histones and protamines. Epigenet Chromatin (2014) 7(1):2. doi: 10.1186/1756-8935-7-2 should be further explored. Understanding the epigenetic regulation in paternal germ cells will pave the way to unravel the coding mechanisms in the transmission of the biological impacts of stress between generations.

\section{AUTHOR CONTRIBUTIONS}

CG and BG prepared the manuscript, conceptualized the idea, and revised the manuscript. All authors contributed to the article and approved the submitted version.
15. Carrell DT, Emery BR, Hammoud S. The aetiology of sperm protamine abnormalities and their potential impact on the sperm epigenome. Int $J$ Androl (2008) 31(6):537-45. doi: 10.1111/j.1365-2605.2008.00872.x

16. Hammoud SS, Nix DA, Zhang H, Purwar J, Carrell DT, Cairns BR. Distinctive chromatin in human sperm packages genes for embryo development. Nature (2009) 460(7254):473-8. doi: 10.1038/nature08162

17. Brykczynska U, Hisano M, Erkek S, Ramos L, Oakeley EJ, Roloff TC, et al. Repressive and active histone methylation mark distinct promoters in human and mouse spermatozoa. Nat Struct Mol Biol (2010) 17(6):679-87. doi: $10.1038 /$ nsmb.1821

18. Jung YH, Sauria M, Lyu X, Cheema MS, Ausio J, Taylor J, et al. Chromatin States in Mouse Sperm Correlate with Embryonic and Adult Regulatory Landscapes. Cell Rep (2017) 18(6):1366-82. doi: 10.1016/j.celrep.2017.01.034

19. Carrell DT. Epigenetics of the male gamete. Fertil Steril (2012) 97(2):267-74. doi: 10.1016/j.fertnstert.2011.12.036

20. Bale TL. Epigenetic and transgenerational reprogramming of brain development. Nat Rev Neurosci (2015) 16(6):332-44. doi: 10.1038/nrn3818

21. Rodgers AB, Morgan CP, Bronson SL, Revello S, Bale TL. Paternal stress exposure alters sperm microRNA content and reprograms offspring HPA stress axis regulation. J Neurosci Off J Soc Neurosci (2013) 33(21):9003-12. doi: 10.1523/JNEUROSCI.0914-13.2013

22. Gapp K, Jawaid A, Sarkies P, Bohacek J, Pelczar P, Prados J, et al. Implication of sperm RNAs in transgenerational inheritance of the effects of early trauma in mice. Nat Neurosci (2014) 17(5):667-9. doi: 10.1038/nn.3695

23. Kiss D, Ambeskovic M, Montina T, Metz GA. Stress transgenerationally programs metabolic pathways linked to altered mental health. Cell Mol Life Sci CMLS (2016) 73(23):4547-57. doi: 10.1007/s00018-016-2272-4

24. Petropoulos S, Matthews SG, Szyf M. Adult glucocorticoid exposure leads to transcriptional and DNA methylation changes in nuclear steroid receptors in the hippocampus and kidney of mouse male offspring. Biol Reprod (2014) 90 (2):43. doi: 10.1095/biolreprod.113.115899

25. Short AK, Fennell KA, Perreau VM, Fox A, O’Bryan MK, Kim JH, et al. Elevated paternal glucocorticoid exposure alters the small noncoding RNA profile in sperm and modifies anxiety and depressive phenotypes in the offspring. Trans Psychiatry (2016) 6(6):e837. doi: 10.1038/tp.2016.109

26. Stankiewicz AM, Swiergiel AH, Lisowski P. Epigenetics of stress adaptations in the brain. Brain Res Bull (2013) 98:76-92. doi: 10.1016/j.brainresbull.2013.07.003

27. Kvetnansky R, Sabban EL, Palkovits M. Catecholaminergic systems in stress: structural and molecular genetic approaches. Physiol Rev (2009) 89(2):535606. doi: 10.1152/physrev.00042.2006

28. Kvetnansky R, Lu X, Ziegler MG. Stress-triggered changes in peripheral catecholaminergic systems. Adv Pharmacol (San Diego Calif) (2013) 68:35997. doi: 10.1016/B978-0-12-411512-5.00017-8

29. Beaulieu JM, Gainetdinov RR. The physiology, signaling, and pharmacology of dopamine receptors. Pharmacol Rev (2011) 63(1):182-217. doi: 10.1124/ pr.110.002642

30. Strosberg AD. Structure, function, and regulation of adrenergic receptors. Protein Sci Publ Protein Soc (1993) 2(8):1198-209. doi: 10.1002/pro.5560020802

31. Pani L, Porcella A, Gessa GL. The role of stress in the pathophysiology of the dopaminergic system. Mol Psychiatry (2000) 5(1):14-21. doi: 10.1038/ sj.mp.4000589 
32. Moriam S, Sobhani ME. Epigenetic effect of chronic stress on dopamine signaling and depression. Genet Epigenet (2013) 5:11-6. doi: 10.4137/ GEG.S11016

33. Maity S, Jarome TJ, Blair J, Lubin FD, Nguyen PV. Noradrenaline goes nuclear: epigenetic modifications during long-lasting synaptic potentiation triggered by activation of $\beta$-adrenergic receptors. J Physiol (2016) 594(4):86381. doi: 10.1113/JP271432

34. Cole SW, Sood AK. Molecular pathways: beta-adrenergic signaling in cancer. Clin Cancer Res (2012) 18(5):1201-6. doi: 10.1158/1078-0432.CCR-11-0641

35. Cotecchia $S$. The $\alpha 1$-adrenergic receptors: diversity of signaling networks and regulation. J Receptor Signal Transduct Res (2010) 30(6):410-9. doi: 10.3109/ 10799893.2010.518152

36. Wilkinson MB, Xiao G, Kumar A, LaPlant Q, Renthal W, Sikder D, et al. Imipramine treatment and resiliency exhibit similar chromatin regulation in the mouse nucleus accumbens in depression models. J Neurosci Off J Soc Neurosci (2009) 29(24):7820-32. doi: 10.1523/JNEUROSCI.0932-09.2009

37. Cadet JL, Jayanthi S, McCoy MT, Beauvais G, Cai NS. Dopamine D1 receptors, regulation of gene expression in the brain, and neurodegeneration. CNS Neurological Disord Drug Targets (2010) 9(5):526-38. doi: 10.2174/ 187152710793361496

38. Corbi G, Conti V, Russomanno G, Longobardi G, Furgi G, Filippelli A, et al. Adrenergic signaling and oxidative stress: a role for sirtuins? Front Physiol (2013) 4:324. doi: 10.3389/fphys.2013.00324

39. Jiang S, Postovit L, Cattaneo A, Binder EB, Aitchison KJ. Epigenetic Modifications in Stress Response Genes Associated With Childhood Trauma. Front Psychiatry (2019) 10:808. doi: 10.3389/fpsyt.2019.00808

40. Chandramohan Y, Droste SK, Arthur JS, Reul JM. The forced swimminginduced behavioural immobility response involves histone $\mathrm{H} 3$ phosphoacetylation and c-Fos induction in dentate gyrus granule neurons via activation of the N-methyl-D-aspartate/extracellular signal-regulated kinase/ mitogen- and stress-activated kinase signalling pathway. Eur J Neurosci (2008) 27(10):2701-13. doi: 10.1111/j.1460-9568.2008.06230.x

41. Gutièrrez-Mecinas M, Trollope AF, Collins A, Morfett H, Hesketh SA, Kersanté F, et al. Long-lasting behavioral responses to stress involve a direct interaction of glucocorticoid receptors with ERK1/2-MSK1-Elk-1 signaling. Proc Natl Acad Sci USA (2011) 108(33):13806-11. doi: 10.1073/pnas.1104383108

42. Bartlett AA, Lapp HE, Hunter RG. Epigenetic Mechanisms of the Glucocorticoid Receptor. Trends Endocrinol Metab: TEM (2019) 30 (11):807-18. doi: 10.1016/j.tem.2019.07.003

43. Sakaue M, Hoffman BB. Glucocorticoids induce transcription and expression of the alpha $1 \mathrm{~B}$ adrenergic receptor gene in DTT1 MF-2 smooth muscle cells. J Clin Invest (1991) 88(2):385-9. doi: 10.1172/JCI115315

44. Kiely J, Hadcock JR, Bahouth SW, Malbon CC. Glucocorticoids down-regulate beta 1-adrenergic-receptor expression by suppressing transcription of the receptor gene. Biochem J (1994) 302(Pt 2):397-403. doi: 10.1042/bj3020397

45. Djureinovic D, Fagerberg L, Hallström B, Danielsson A, Lindskog C, Uhlén M, et al. The human testis-specific proteome defined by transcriptomics and antibody-based profiling. Mol Hum Reprod (2014) 20(6):476-88. doi: 10.1093/ molehr/gau018

46. Guo JH, Huang Q, Studholme DJ, Wu CQ, Zhao Z. Transcriptomic analyses support the similarity of gene expression between brain and testis in human as well as mouse. Cytogenetic Genome Res (2005) 111(2):107-9. doi: 10.1159/ 000086378

47. Uhlén M, Fagerberg L, Hallström BM, Lindskog C, Oksvold P, Mardinoglu A, et al. Proteomics. Tissue-based map of the human proteome. Sci (New York NY) (2015) 347(6220):1260419. doi: 10.1126/science.1260419

48. Day R, Salzet M. The neuroendocrine phenotype, cellular plasticity, and the search for genetic switches: redefining the diffuse neuroendocrine system. Neuro Endocrinol Lett (2002) 23(5-6):447-51.

49. Toni R. The neuroendocrine system: organization and homeostatic role. J Endocrinol Invest (2004) 27(6 Suppl):35-47.

50. Prince FP. Ultrastructural evidence of indirect and direct autonomic innervation of human Leydig cells: comparison of neonatal, childhood and pubertal ages. Cell Tissue Res (1992) 269(3):383-90. doi: 10.1007/BF00353893

51. Prince FP. Ultrastructural evidence of adrenergic, as well as cholinergic, nerve varicosities in relation to the lamina propria of the human seminiferous tubules during childhood. Tissue Cell (1996) 28(5):507-13. doi: 10.1016/ s0040-8166(96)80053-x
52. Mayerhofer A, Danilchik M, Pau KY, Lara HE, Russell LD, Ojeda SR. Testis of prepubertal rhesus monkeys receives a dual catecholaminergic input provided by the extrinsic innervation and an intragonadal source of catecholamines. Biol Reprod (1996) 55(3):509-18. doi: 10.1095/biolreprod55.3.509

53. Mayerhofer A, Frungieri MB, Fritz S, Bulling A, Jessberger B, Vogt HJ. Evidence for catecholaminergic, neuronlike cells in the adult human testis: changes associated with testicular pathologies. J Androl (1999) 20(3):341-7. doi: 10.1002/j.1939-4640.1999.tb02527.x

54. Frungieri MB, Urbanski HF, Höhne-Zell B, Mayerhofer A. Neuronal elements in the testis of the rhesus monkey: ontogeny, characterization and relationship to testicular cells. Neuroendocrinology (2000) 71(1):43-50. doi: 10.1159/ 000054519

55. Ramírez-Reveco A, Villarroel-Espíndola F, Rodríguez-Gil JE, Concha III. Neuronal signaling repertoire in the mammalian sperm functionality. Biol Reprod (2017) 96(3):505-24. doi: 10.1095/biolreprod.116.144154

56. Adeoya-Osiguwa SA, Gibbons R, Fraser LR. Identification of functional alpha2- and beta-adrenergic receptors in mammalian spermatozoa. Hum Reprod (Oxford England) (2006) 21(6):1555-63. doi: 10.1093/humrep/ del016/

57. Otth C, Torres M, Ramírez A, Fernandez JC, Castro M, Rauch MC, et al. Novel identification of peripheral dopaminergic D2 receptor in male germ cells. J Cell Biochem (2007) 100(1):141-50. doi: 10.1002/jcb.21037

58. Ramírez AR, Castro MA, Angulo C, Ramió L, Rivera MM, Torres M, et al. The presence and function of dopamine type 2 receptors in boar sperm: a possible role for dopamine in viability, capacitation, and modulation of sperm motility. Biol Reprod (2009) 80(4):753-61. doi: 10.1095/biolreprod.108.070961

59. Czech DP, Lee J, Sim H, Parish CL, Vilain E, Harley VR. The human testisdetermining factor SRY localizes in midbrain dopamine neurons and regulates multiple components of catecholamine synthesis and metabolism. J Neurochem (2012) 122(2):260-71. doi: 10.1111/j.1471-4159.2012.07782.x

60. Lee J, Pinares-Garcia P, Loke H, Ham S, Vilain E, Harley VR. Sex-specific neuroprotection by inhibition of the Y-chromosome gene, SRY, in experimental Parkinson's disease. Proc Natl Acad Sci USA (2019) 116 (33):16577-82. doi: 10.1073/pnas.1900406116

61. Sinclair D, Purves-Tyson TD, Allen KM, Weickert CS. Impacts of stress and sex hormones on dopamine neurotransmission in the adolescent brain. Psychopharmacology (2014) 231(8):1581-99. doi: 10.1007/s00213-013-3415-z

62. Lee S, Miselis R, Rivier C. Anatomical and functional evidence for a neural hypothalamic-testicular pathway that is independent of the pituitary. Endocrinology (2002) 143(11):4447-54. doi: 10.1210/en.2002-220392

63. Vassoler FM, White SL, Schmidt HD, Sadri-Vakili G, Pierce RC. Epigenetic inheritance of a cocaine-resistance phenotype. Nat Neurosci (2013) 16(1):427. doi: $10.1038 / \mathrm{nn} .3280$

64. Le Q, Yan B, Yu X, Li Y, Song H, Zhu H, et al. Drug-seeking motivation level in male rats determines offspring susceptibility or resistance to cocaineseeking behaviour. Nat Commun (2017) 8:15527. doi: 10.1038/ncomms15527

65. González B, Pantoja C, Sosa MH, Vitullo AD, Bisagno V, González CR. Cocaine alters the mouse testicular epigenome with direct impact on histone acetylation and DNA methylation marks. Reprod Biomed Online (2018) 37 (3):269-78. doi: 10.1016/j.rbmo.2018.05.014

66. González B, Gancedo SN, Garazatua S, Roldán E, Vitullo AD, González CR. Dopamine Receptor D1 Contributes to Cocaine Epigenetic Reprogramming of Histone Modifications in Male Germ Cells. Front Cell Dev Biol (2020) 8:216. doi: $10.3389 /$ fcell.2020.00216

67. González CR, González B, Matzkin ME, Muñiz JA, Cadet JL, Garcia-Rill E, et al. Psychostimulant-Induced Testicular Toxicity in Mice: Evidence of Cocaine and Caffeine Effects on the Local Dopaminergic System. PloS One (2015) 10(11):e0142713. doi: 10.1371/journal.pone.0142713

68. Williams GV, Castner SA. Under the curve: critical issues for elucidating D1 receptor function in working memory. Neuroscience (2006) 139(1):263-76. doi: 10.1016/j.neuroscience.2005.09.028

69. Hammoud SS, Low DH, Yi C, Carrell DT, Guccione E, Cairns BR. Chromatin and transcription transitions of mammalian adult germline stem cells and spermatogenesis. Cell Stem Cell (2014) 15(2):239-53. doi: 10.1016/ j.stem.2014.04.006

70. Soumillon M, Necsulea A, Weier M, Brawand D, Zhang X, Gu H, et al. Cellular source and mechanisms of high transcriptome complexity in the mammalian testis. Cell Rep (2013) 3(6):2179-90. doi: 10.1016/j.celrep.2013.05.031 
71. Maezawa S, Hasegawa K, Yukawa M, Kubo N, Sakashita A, Alavattam KG, et al. Polycomb protein SCML2 facilitates H3K27me3 to establish bivalent domains in the male germline. Proc Natl Acad Sci USA (2018) 115(19):495762. doi: $10.1073 /$ pnas. 1804512115

72. La HM, Mäkelä JA, Chan AL, Rossello FJ, Nefzger CM, Legrand J, et al. Identification of dynamic undifferentiated cell states within the male germline. Nat Commun (2018) 9(1):2819. doi: 10.1038/s41467-018-04827-z

73. Green CD, Ma Q, Manske GL, Shami AN, Zheng X, Marini S, et al. A Comprehensive Roadmap of Murine Spermatogenesis Defined by SingleCell RNA-Seq. Dev Cell (2018) 46(5):651-67.e10. doi: 10.1016/j.devcel. 2018.07.025

74. Hermann BP, Cheng K, Singh A, Roa-De La Cruz L, Mutoji KN, Chen IC, et al. The Mammalian Spermatogenesis Single-Cell Transcriptome, from Spermatogonial Stem Cells to Spermatids. Cell Rep (2018) 25(6):1650-67.e8. doi: 10.1016/j.celrep.2018.10.026

75. Rossi SP, Walenta L, Rey-Ares V, Köhn FM, Schwarzer JU, Welter H, et al. Alpha 1 adrenergic receptor-mediated inflammatory responses in human testicular peritubular cells. Mol Cell Endocrinol (2018) 474:1-9. doi: 10.1016/ j.mce.2018.01.027

76. Thanoi S, Janphet S, Nudmamud-Thanoi S. Changes of dopamine D2, alphal adrenergic receptor expressions and developmental stages of seminiferous tubule in rat testis after methamphetamine administration: A preliminary study. Songklanakarin J Sci Technol (2020) 42(4):928-34.

77. Mhaouty-Kodja S, Lozach A, Habert R, Tanneux M, Guigon C, Brailly-Tabard S, et al. Fertility and spermatogenesis are altered in \{alpha\}1b-adrenergic receptor knockout male mice. J Endocrinol (2007) 195(2):281-92. doi: 10.1677/JOE-07-0071
78. Shirakawa T, Yaman-Deveci R, Tomizawa S, Kamizato Y, Nakajima K, Sone H, et al. An epigenetic switch is crucial for spermatogonia to exit the undifferentiated state toward a Kit-positive identity. Dev (Cambridge England) (2013) 140(17):3565-76. doi: 10.1242/dev.094045

79. La Salle S, Trasler J. Epigenetic patterning in male germ cells: Importance of DNA methylation to progeny outcome. In: C De Jonge, C Barratt, editors. The Sperm Cell: Production, Maturation, Fertilization, Regeneration. Cambridge: Cambridge University Press (2006). p. 279-322. doi: 10.1017/CBO9780511545115.012

80. Zipperly ME, Sultan FA, Graham GE, Brane AC, Simpkins NA, Carullo N, et al. Regulation of dopamine-dependent transcription and cocaine action by Gadd45b. Neuropsychopharmacol Off Publ Am Coll Neuropsychopharmacol (2020). doi: 10.1038/s41386-020-00828-z

81. Lepack AE, Werner CT, Stewart AF, Fulton SL, Zhong P, Farrelly LA, et al. Dopaminylation of histone $\mathrm{H} 3$ in ventral tegmental area regulates cocaine seeking. Sci (New York NY) (2020) 368(6487):197-201. doi: 10.1126/ science.aaw8806

Conflict of Interest: The authors declare that the research was conducted in the absence of any commercial or financial relationships that could be construed as a potential conflict of interest.

Copyright (0) 2021 González and González. fonc.2021.616722 This is an open-access article distributed under the terms of the Creative Commons Attribution License (CC BY). The use, distribution or reproduction in other forums is permitted, provided the original author(s) and the copyright owner(s) are credited and that the original publication in this journal is cited, in accordance with accepted academic practice. No use, distribution or reproduction is permitted which does not comply with these terms. 